\author{
А.А. Оприщенко, К.А. Бодаченко, А.А. Штутин
}

Республиканский травматологический центр, Донецк

\title{
ТАКТИКА СПЕЦИАЛИЗИРОВАННОЙ ПОМОЩИ РАНЕНЫМ С ОГНЕСТРЕЛЬНЫМИ ПЕРЕЛОМАМИ КОСТЕЙ ГОЛЕНИ
}

В условиях военных конфликтов низкой интенсивности огнестрельные переломы костей голени составляют более половины всех огнестрельных переломов длинных костей [1-3]. Они характеризуются тяжестью и протяженностью повреждения тканей, сложной морфологией, высоким риском развития, как ранних, так и поздних осложнений, и неудовлетворительных исходов [4-7]. В военно-медицинской практике последних десятилетий преобладает этапный подход к лечению данной патологии $[1,2$, 8]. При этом первичная стабилизация перелома на этапе мобильных госпиталей первой линии выполняется наиболее простыми конструкциями стержневых аппаратов, а окончательный остеосинтез производится в тыловых госпиталях после заживления ран, как правило, погружными, по возможности миниинвазивными, методами $[1,2]$. В значительной мере такая тактика обусловлена особенностями организации военно-медицинской службы, которой присуща четкая регламентация уровня материальнотехнического обеспечения и объема медицинской помощи. В условиях локального вооруженного конфликта в Донбассе большинство раненых с огнестрельными переломами голени первично госпитализируются в специализированный травматологический центр, что дает возможность дифференцированно подойти к выбору объема, очередности и последовательности лечебных мероприятий. В доступной литературе возможности дифференцированного подхода к лечению огнестрельных переломов голени в гражданских лечебных учреждениях освещены недостаточно.

\section{ЦЕЛ b}

Анализ тактики специализированного лечения раненых с огнестрельными переломами костей голени в учреждении гражданского здравоохранения третьего уровня в период локального военного конфликта.

\section{МАТЕРИАЛ И МЕТОДЫ}

Проведен ретроспективный анализ материалов лечения 83 раненых с огнестрельными переломами костей голени в Республиканском травматологическом центре в период 20152017 гг. Согласно критериям включения/исключения раненые, которым производились первичные ампутации, исключались, так же в исследование не включали пострадавших детского возраста и раненых, переведенных из других учреждений в срок более 24 ч от момента ранения. Все раненые были мужчины, средний возраст $34,7 \pm 4,3$ года (20-48). Пулевые ранения имели место у 29 (34,9\%) пострадавших, взрывная травма - у 54 (65,1\%). Изолированные повреждения сегментов опорно-двигательного аппарата установлены у 34 (41,0\%) раненых, множественные - 31 (37,3\%), сочетанные - 18 (21,7\%). Шок 2-3 степени имел место у 18 (21,7\%) раненых. Тяжесть повреждений конечностей оценивалась по шкале ВПХ-П (ОР) [9] и составила $3,2 \pm 0,3$ баллов. Общая тяжесть повреждений $4,1 \pm 0,2$ баллов. Средний срок доставки раненых в клинику составил 98,7 $\pm 11,2$ мин. (50-190). Открытые переломы IIIA типа (по классификации Gustilo-Andersen) [10, 11] были диагностированы в 34 (41,0\%) наблюдениях, IIIB - 46 (55,4\%) случаях, IIIC - 3 (3,6\%). По локализации преобладали переломы диафиза - 56 (67,5\%), проксимального метаэпифиза - 12 (14,5\%), дистального метаэпифиза - 15 (18,1\%). Многооскольчатые (фрагментарные и полифрагментарные) переломы имели место у $74(89,2 \%)$ раненых.

Все раненые в экстренном порядке были оперированы в сроки до 12 часов от момента поступления в клинику. Производилась первичная хирургическая обработка ран, стабилизация перелома или окончательный остеосинтез поврежденных сегментов аппаратами внешней фикса-

() А.А. Оприщенко, К.А. Бодаченко, А.А. Штутин, 2018 (c) Университетская Клиника, 2018 
ции стержневого или спице-стержневого типа. Системная антибиотикопрофилактика проводилась цефалоспоринами 2 поколения.

Решение о применении вакуумной терапии принимали в срок от 3 до 15 суток в зависимости от характера течения раневого процесса. Показаниями к применению вакуумной терапии считали глубокие раневые дефекты с наличием обильного отделяемого, продолжающийся некроз мышц без четкой демаркации, развитие компартмент-синдрома.

Лечение ран методом отрицательного давления осуществляли с помощью устройств IMPACTM306, GOMCO 6003 (США). При наложении повязок использовалась стерильная гидрофильная полиуретановая губка с размером пор от 400 до 2000 микрометров, которую дополнительно обрабатывали антисептиком тиротрицином. Во время повторных оперативных вмешательств, проведения некрэктомий в имеющийся мягкотканный дефект вкладывали стерильный пористый материал по контуру и размерам раны. Повязки фиксировались при помощи прозрачного адгезивного покрытия в виде стерильной пленки TEGADERMFILM 3M или IOBAN 3M. C помощью внешнего контрольного устройства в системе вакуумной аппаратуры поддерживался диапазон значений отрицательного давления от 90 до $120 \mathrm{mmHg}(12-16$ кПа).

На основании ретроспективного анализа результатов лечения материал историй болезней был разделен на две группы. У пострадавших первой группы $(\mathrm{n}=53)$ имел место неосложненный характер клинического течения, у пострадавших второй $(\mathrm{n}=30)$ - осложненный (развитие ранних или поздних местных инфекционногнойных осложнений, нарушение консолидации переломов голени при технически правильном выполнении остеосинтеза). По демографическим параметрам и характеру первичного повреждения пострадавшие в двух группах значимо не различались.

Полученные результаты обработаны методами описательной статистики с расчетом доли (в процентах), средней величины, ошибки средней. Статистическую значимость различий средних величин в двух группах оценивали критерием Манна-Уитни с помощью пакета программ «Statistica for Windows» 6.0.

\section{РЕЗУЛЬТАТЫ И ОБСУЖДЕНИЕ}

В группе с неосложненным течением в 42 случаях при оказании первичной специализированной помощи использовалась тактика сберегательной первичной хирургической обработки и стабилизации перелома аппаратами внешней фиксации стержневого или спице- стержневого типа. В 11 наблюдениях при изолированных переломах IIIA типа выполняли репозицию и полноценный остеосинтез аппаратами спице-стержневого типа. При этом первичный шов был наложен в 9 наблюдениях у раненых с относительно небольшой зоной повреждения сегмента преимущественно вторичными и третичными ранящими агентами. У раненых, которым рана оставлялась первично открытой, в 19 наблюдениях при наличии дефекта покровных тканей, выраженной раневой экссудации и признаках компартмент-синдрома, начиная с 3-5 суток, применялась вакуумная терапия ран. В 11 случаях применена планируемая пластика локальными кровоснабжаемыми лоскутами для закрытия дефекта в сроки от 7 до 18 суток.

В послеоперационном периоде назначали комплекс консервативной терапии, направленный на оптимизацию региональной гемодинамики и тканевого обмена. Антибактериальная терапия проводилась согласно данным антибиотикограмм - чаще всего это были препараты группы фторхинолонов, цефалоспоринов в сочетании с сульбактамом или с метронидазолом. Вазоактивная терапия была направлена на снятие спазма сосудов (спазмолитики), улучшение реологических свойств крови, повышение толерантности мышечной ткани к ишемии, уменьшение отека пораженной конечности. Выполнялось адекватное обезболивание (в первые сутки применяли наркотические анальгетики), в последующем - ненаркотические. Профилактика и лечение посттравматической нейропатии осуществлялось комбинированными комплексными препаратами и витамином С. Профилактика кислородной задолженности тканей проводилась препаратами $\alpha$-липоевой кислоты, а также витамином Е. В качестве иммуностимулятора использовался тилорон.

Окончательный остеосинтез аппаратами внешней фиксации спице-стержневого типа производился в срок от 7 до 23 суток. Число оперативных вмешательств на одного раненого на голени составило в среднем $4,7 \pm 1,5$ с учетом повторных планируемых хирургических обработок и замены VAC-повязок. Средний срок пребывания на койке составил $47,5 \pm 8,2$ суток. У раненых с изолированными переломами IIIA типа и первичным окончательным остеосинтезом число оперативных вмешательств составило $2,4 \pm 0,8$, а средний срок пребывания на койке $-28,6 \pm 3,5$ суток, что статистически значимо отличается от показателей в группе $(\mathrm{p}<0,05)$. На наш взгляд, эти данные указывают на обоснованность использования тактики первичного окончательного внешнего остеосинтеза по четко ограниченным показаниям. 
В группе с осложненным течением «радикальная» первичная хирургическая обработка с наложением первичного шва применялась у 21 раненого. Полноценный первичный остеосинтез аппаратами внешней фиксации спицестрежневого типа производился в 27 наблюдениях. Ранние раневые осложнения были выявлены у 24 раненых в срок от 5 до 9 суток. У 6 раненых прогрессирующий некроз покровных тканей после наложения первичного шва привел к обнажению костных фрагментов в срок от 14 до 28 суток. Вследствие этого отмечено позднее начало вакуумной терапии при развитии раневых осложнений - в среднем $15,7 \pm 4,8$ (12-23) суток. Пластическое закрытие мягкотканных дефектов вынужденно задерживалось до 37,0ะ9,7 (26-45) суток. Детальный анализ материалов лечения второй группы раненых показал, что попытка проведения «радикальной» первичной хирургической обработки и первичного окончательного остеосинтеза у 18 раненых были предприняты ошибочно, без должного учета тяжести повреждения и риска развития осложнений. Еще у 6 раненых были выявлены ошибки в тактике послеоперационного лечения - недостаточный объем инфузионной и медикаментозной терапии, нерациональное местное лечение раны и другие. Средняя длительность стационарного лече-

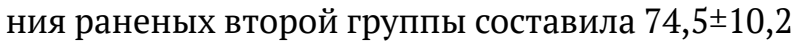
суток, что значимо отличается от раненых первой группы $(p<0,05)$. Существенно возрастало и число оперативных вмешательств, в основном направленных на борьбу с развивающимися осложнениями $-7,8 \pm 1,7$, что значимо отличается от показателя первой группы (p<0,05).

Анализ структуры осложнений показывает, что в остром периоде закономерно преобладали инфекционные и некротические осложнения, обусловленные продолжающимся некрозом мышц, формированием гнойных «затеков» - 19 случаев. Они требовали широкого рассечения ран, этапных некрэктомий с применением вакуумной терапии и последующим закрытием пластическими методами. Еще в 8 случаях имел место прогрессирующий некроз покровных тканей, также потребовавший этапных некрэктомий и последующей этапной кожной пластики. Огнестрельный остеомиелит развился в 9 наблюдениях, в 7 из которых была произведена сегментарная резекция большеберцовой кости с последующим билокальным дистракционным замещением костного дефекта. Вынужденный «перемонтаж» аппаратов внешней фиксации осуществляли во всех наблюдениях неоднократно. Из поздних осложнений следует выделить случаи нарушенной консолидации перелома - 20, обусловленные отсутствием полноцен- ного мягкотканного покрова и, соответственно, должного уровня васкуляризации.

Следует отметить, что хронологически наибольшее число пациентов с осложненным течением (19) относится к раннему периоду военного конфликта - 2015 г. В последующем в связи с накоплением опыта и унификацией лечебной тактики число осложнений снижается: 6 - в 2016 г., 5 - в 2017 г.

При этом обращает на себя внимание возможность и перспективность применения тактики окончательного наружного остеосинтеза в ограниченной группе раненых по четко определенным показаниям. К таковым мы относим изолированные переломы диафиза голени IIIA типа при условии поступления в специализированный стационар в течение первых 6 часов от момента ранения. Во всех остальных случаях считаем более обоснованным применение этапного подхода - сберегательной первичной хирургической обработки, отказ от первичного закрытия раны, первичную стабилизацию перелома щадящими методами наружной фиксации аппаратами стержневого либо спицестержневого типа. Кожно-пластические вмешательства, направленные на воссоздание полноценного мягкотканного покрова в зоне перелома и, соответственно, на его реваскуляризацию, должны быть произведены в максимально возможные краткие сроки после ранения, что позволяет избежать формирования остеонекроза обнаженной кости и создать оптимальные условия остеорегенерации.

Сопоставление наших данных с результатами отечественных и зарубежных исследователей показывает преимущества современного этапного подхода к лечению огнестрельных переломов костей голени [8, 12]. Первичная госпитализация раненых в специализированный центр позволяет максимально уменьшить число этапов эвакуации, заранее планировать программу специализированного лечения с использованием оптимальных хирургических технологий, что обусловливает преемственность и эффективность лечения. В условиях вооруженного конфликта низкой интенсивности все раненые с огнестрельными переломами костей голени должны концентрироваться в специализированном травматологическом центре, располагающем достаточным кадровым и материальнотехническим обеспечением.

\section{В Ы В О д Ы}

Тактика лечения огнестрельных переломов костей голени в специализированных гражданских медицинских учреждениях в условиях военных конфликтов низкой интенсивности мо- 
жет носить дифференцированный характер в зависимости от комплексной оценки тяжести состояния раненого, тяжести повреждения и медико-тактических условий.

Основным принципом первичной специализированной помощи раненым с огнестрельными переломами голени является сберегательная первичная хирургическая обработка и первичная стабилизация перелома аппаратом внешней фиксации.

Применение первично-восстановительной тактики, предусматривающей радикальную первичную хирургическую обработку и окончательный остеосинтез аппаратами внешней фиксации, обосновано у раненых с изолированными повреждениями опосредованными ранящими агентами на фоне общего стабильного состояния раненых.

Лечение огнестрельных переломов голени должно носить этапный комплексный характер, включая современные технологии закрытия раны и наружного внеочагового остеосинтеза.

\section{А.А. Оприщенко, К.А. Бодаченко, А.А. Штутин}

\section{Республиканский травматологический центр, Донецк}

\section{ТАКТИКА СПЕЦИАЛИЗИРОВАННОЙ ПОМОЩИ РАНЕНЫМ С ОГНЕСТРЕЛЬНЫМИ ПЕРЕЛОМАМИ КОСТЕЙ ГОЛЕНИ}

Огнестрельные переломы костей голени составляют более половины всех огнестрельных переломов длинных костей в условиях военных конфликтов.

Цель: анализ тактики специализированного лечения раненых с огнестрельными переломами костей голени в учреждении гражданского здравоохранения третьего уровня в период локального военного конфликта.

Материал и методы. Проведен ретроспективный анализ материалов лечения 83 раненых с огнестрельными переломами костей голени. Все раненые были мужчины, средний возраст 34,7士4,3 года (20-48). Пулевые ранения имели место у 29 (34,9\%) пострадавших, взрывная травма - у 54 (65,1\%). Изолированные повреждения сегментов опорно-двигательного аппарата установлены у 34 (41,0\%) раненых, множественные - 31 (37,3\%), сочетанные - 18 (21,7\%). Открытые переломы IIIA типа - 34 (41,0\%), IIIB - 46 (55,4\%), IIIC - 3 (3,6\%). По локализации преобладали переломы диафиза - 56 (67,5\%), проксимального метаэпифиза - 12 (14,5\%), дистального метаэпифиза - 15 (18,1\%). Многооскольчатые (фрагментарные и полифрагмен- тарные) переломы имели место у 74 (89,2\%) раненых. На основании ретроспективного анализа результатов лечения материал историй болезней был разделен на две группы: 1 группа $(n=53)$ с неосложненным клиническим течением, 2 группа $(\mathrm{n}=30)$ - с наличием осложнений.

Результаты. В 1 группе число операций на одного

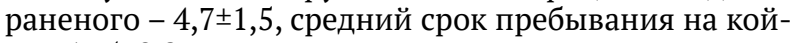
ке $-47,5 \pm 8,2$ суток. У раненых с изолированными переломами IIIA типа и первичным окончательным остеосинтезом число оперативных вмешательств $-2,4 \pm 0,8$, а средний срок пребывания на койке - 28,6 $\pm 3,5$ суток. Bo 2 группе средняя длительность стационарного ле-

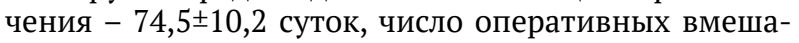
тельств - 7,8 $\pm 1,7$.

Заключение. Лечение огнестрельных переломов голени должно носить этапный комплексный дифференцированный характер, включая современные технологии закрытия раны и наружного внеочагового остеосинтеза.

Ключевые слова: огнестрельные переломы голени, лечение, осложнения.

\section{A.A. Oprishchenko, K.A. Bodachenko, A.A. Shtutin}

\section{Republican Trauma Center, Donetsk}

\section{TACTICS OF SPECIALIZED TREATMENT OF GUNSHOT SHIN FRACTURES}

Gunshot shin fractures constitute more than half of all gunshot fractures of long bones in military conflicts.

Purpose: analysis of the tactics of specialized treatment of gunshot shin fractures in a third-level civilian health facility during a local military conflict.

Material and methods. A retrospective analysis of the treatment of 83 wounded with gunshot shin fractures was carried out. All the injured were men, average age was $34.7 \pm 4.3$ years [20-48]. Bullet injuries occurred in 29 (34.9\%) victims, explosive injuries - in 54 (65.1\%). Isolated injuries of the segments of the musculoskeletal system were found in 34 (41.0\%) injured, multiple - 31 (37.3\%), combined - 18 (21.7\%). Open fractures of type
IIIA - 34 (41.0\%), IIIB - 46 (55.4\%), IIIC - 3 (3.6\%). The localization was dominated by fractures of the diaphysis - $56(67.5 \%)$, proximal radius - $12(14.5 \%)$, distal radius - 15 (18.1\%). Multifragmentary (fragmentary and polyfragmentary) fractures occurred in 74 (89.2\%). Based on a retrospective analysis of the results of treatment, the case histories were divided into two groups: group $1(n=53)$ with an uncomplicated clinical course, group 2 $(n=30)$ with complications.

Results. In group 1 , the number of operations per wounded person was $4.7 \pm 1.5$, the average duration of staying in bed was $47.5 \pm 8.2$ days. In the wounded with isolated type IIIA fractures and primary final osteosyn- 
thesis, the number of surgical interventions is $2.4 \pm 0.8$, and the average length of staying in bed is $28.6 \pm 3.5$ days. In group 2, the average duration of inpatient treatment was $74.5 \pm 10.2$ days, the number of surgical interventions was $7.8 \pm 1.7$.
Conclusion. The treatment of gunshot shin fractures should be of a gradual, complex, differentiated nature, including modern technologies of wound closure and external osteosynthesis.

Key words: gunshot shin fractures, treatment, complications.

\section{ЛИТЕРАТУРА}

1. Гуманенко Е.К., Самохвалов И.М. Военно-полевая хирургия локальных войн и вооруженных конфликтов: Руководство для врачей. М.: ГЭОТАР-Медиа; 2011. 672.

2. Ганин Е.В. Лечебно-транспортная иммобилизация переломов длинных костей конечностей в системе этапного лечения раненых и пострадавших: дис. канд. мед. наук.- С-Петербург; 2016. 221.

3. Belmont P.J. Jr., McCriskin B.J., Hsiao M.S. [et al.] The nature and incidence of musculoskeletal combat wounds in Iraq and Afghanistan (2005-2009). J Orthop Trauma. 2013; 27 (5): e107-13. doi:10.1097/BOT.0b013e3182703188

4. Owens B.D., Kragh J.F. Jr., Wenke J.C. [et al.] Combat wounds in operation Iraqi Freedom and operation Enduring Freedom. J Trauma. 2008; 64: 295-299.

5. Bartlett C.S., Helfet D.L., Hausman M.R., Strauss E. Ballistics and gunshot wounds: effects on musculoskeletal tissues. J Am AcadOrthop Surg. 2000; 8 (1): 21-36.

6. Dougherty P.J., Najibi S., Silverton C., Vaidya R. Gunshot wounds: epidemiology, wound ballistics, and soft-tissue treatment. Instr Course Lect. 2009; 58: 131-139.

7. Rhee P.M., Moore E.E., Joseph B., Tang A., Pandit V., Vercruysse G. Gunshot wounds: A review of ballistics, bullets, weapons, and myths. J Trauma Acute Care Surg. 2016; 80 (6): 853-867. doi: 10.1097/TA.0000000000001037

8. Jeffery S.L. The Management of Combat Wounds: The British Military Experience. Adv Wound Care (New Rochelle). 2016; 5 (10): 464-473. doi: 10.1089/wound.2015.0653

9. Гуманенко Е.К., Бояринцев В.В., Супрун Т.Ю., Ляшедько П.П. Объективная оценка тяжести травм. СПб.: Воен.-мед.акад.; 1999. 110.

10. Gustilo R.B., Anderson J.T. Prevention of infection in the treatment of one thousand and twenty-five open fractures of long bones: retrospective and prospective analyses. J Bone Joint Surg Am. 1976; 58: 453-458

11. Gustilo R.B., Mendoza R.M., Williams D.N. Problems in management of type III (severe) open fractures: a new classification of type III open fractures. J Trauma. 1984; 24: 742-746. doi:10.1097/00005373-198408000-00009

12. Maurya S., Bhandari P.S. Negative Pressure Wound Therapy in the Management of Combat Wounds: A Critical Review. Adv Wound Care (NewRochelle). 2016; 5 (9): 379389. doi:10.1089/wound.2014.0624

\section{REFERENCES}

1. Gumanenko E.K., Samokhvalov I.M. Voenno-polevaya khirurgiya lokal'nykh voin i vooruzhennykh konfliktov: Rukovodstvo dlya vrachei. M.: GEOTAR-Media; 2011. 672 (in Russian).

2. Ganin E.V. Lechebno-transportnaya immobilizatsiya perelomov dlinnykh kostei konechnostei v sisteme etapnogo lecheniya ranenykh i postradavshikh: dis. kand. med. nauk.- S-Peterburg; 2016. 221(in Russian).

3. Belmont P.J. Jr., McCriskin B.J., Hsiao M.S. [et al.] The nature and incidence of musculoskeletal combat wounds in Iraq and Afghanistan (2005-2009). J Orthop Trauma. 2013; 27 (5): e107-13. doi:10.1097/BOT.0b013e3182703188

4. Owens B.D., Kragh J.F. Jr., Wenke J.C. [et al.] Combat wounds in operation Iraqi Freedom and operation Enduring Freedom. J Trauma. 2008; 64: 295-299.

5. Bartlett C.S., Helfet D.L., Hausman M.R., Strauss E. Ballistics and gunshot wounds: effects on musculoskeletal tissues. J Am AcadOrthop Surg. 2000; 8 (1): 21-36.

6. Dougherty P.J., Najibi S., Silverton C., Vaidya R. Gunshot wounds: epidemiology, wound ballistics, and soft-tissue treatment. Instr Course Lect. 2009; 58: 131-139.

7. Rhee P.M., Moore E.E., Joseph B., Tang A., Pandit V., Vercruysse G. Gunshot wounds: A review of ballistics, bullets, weapons, and myths. J Trauma Acute Care Surg. 2016; 80 (6): 853-867. doi: 10.1097/TA.0000000000001037

8. Jeffery S.L. The Management of Combat Wounds: The British Military Experience. Adv Wound Care (New Rochelle). 2016; 5 (10): 464-473. doi: 10.1089/wound.2015.0653

9. Gumanenko E.K., Boyarintsev V.V., Suprun T.Yu., Lyashed'ko P.P. Ob»ektivnaya otsenka tyazhesti travm. SPb.: Voen.-med.akad.; 1999. 110(in Russian).

10. Gustilo R.B., Anderson J.T. Prevention of infection in the treatment of one thousand and twenty-five open fractures of long bones: retrospective and prospective analyses. J Bone Joint Surg Am. 1976; 58: 453-458

11. Gustilo R.B., Mendoza R.M., Williams D.N. Problems in management of type III (severe) open fractures: a new classification of type III open fractures. J Trauma. 1984; 24: 742-746. doi:10.1097/00005373-198408000-00009

12. Maurya S., Bhandari P.S. Negative Pressure Wound Therapy in the Management of Combat Wounds: A Critical Review. Adv Wound Care (NewRochelle). 2016; 5 (9): 379389. doi:10.1089/wound.2014.0624 